\title{
Médicos para o SUS: gestão do trabalho e da educação na saúde no olho do furacão!
}

\author{
Physicians for the Brazilian National Health System (SUS): management of healthcare education \\ and work at the eye of the hurricane!
}

¡ Médicos para el Sistema Único de Salud (SUS): gestión del trabajo y de la educación em el ojo del huracán!

O artigo apresenta o problema do provimento e da fixação de médicos no Brasil, com foco na atenção básica, e as iniciativas políticas a ele endereçadas, particularmente, o Programa de Valorização da Atenção Básica (PROVAB). Inspirando-se em Foucault, as autoras utilizam como categorias analíticas: o poder, o saber, o trabalho e a meritocracia; e, também, como referenciais para a análise: formação médica, educação permanente, saberes tecnológicos, poder médico, relação médico-paciente, autonomia, disputa entre corporações e governo, entre outros.

Difícil a escolha de por onde desenvolver o debate, uma vez que tudo instiga a ação: o tema, o modo como se contou a história, como se fez a análise, como foram usados os referenciais anunciados etc.

À luz da teoria de Foucault, creio ser possível reconstruir a história com uma perspectiva mais crítica. Durante todo o processo de construção do SUS, as agendas da gestão do trabalho e da educação na saúde vinham sendo negligenciadas - até o momento atual, em que partes delas ganham importância na intervenção política do governo federal. Explicações? A perspectiva dominante - de considerar trabalhadores em saúde como recursos e usuários como objeto de intervenção - visibiliza saberes (conceitos) e poderes. Trabalhadores-recursos, insumos do processo de trabalho e usuários-objeto de intervenção não são reconhecidos como atores ativos da produção do SUS. Mas são atores ativos, que operam na micropolítica do cotidiano - disputando projetos, fazendo escolhas, ocupando, uns, lugares de trabalho, e não outros - e também na definição das políticas, como corporação, impondo ou embargando agendas e processos de negociação.

A omissão em relação à agenda da gestão do trabalho e da educação tem consequências graves, sobretudo, quando o sistema público convive com um sistema privado de saúde. O SUS, assim, acumula derrotas sucessivas: na disputa do imaginário público em relação ao conceito e à produção da saúde, na disputa pelo modelo de atenção, na produção das expectativas e sonhos dos futuros e dos atuais trabalhadores da saúde, na orientação da formação dos profissionais de saúde - tanto em relação ao perfil como na localização de cursos de graduação, residências etc. Nos últimos doze anos, houve iniciativas, mas, no geral, tímidas, localizadas, débeis, diante da ferocidade da disputa social enfrentada.

${ }^{1}$ Departamento de Prática de Saúde Pública Faculdade de Saúde Pública, Universidade de São Paulo. Av. Dr. Arnaldo, 715 São Paulo, SP, Brasil. 01246-904 laura.macruz@usp.br 
Faltam médicos no Brasil? Sim! E a situação atual é uma coprodução da omissão dos governos e da atuação ativa da corporação médica e dos agentes de mercado na saúde. De quantos médicos precisamos? Depende do modelo de atenção, dos arranjos tecnológicos do trabalho, da aposta ou não na produção de redes vivas, de espaços de encontro e diálogo entre trabalhadores etc. Mas, muito além do número, é preciso discutir quanto a que médicos precisamos. Não apenas se serão generalistas ou especialistas. Está em questão a base da formação: orientada ao biológico ou às necessidades dos usuários, centrada em procedimentos ou na produção do cuidado, produzida para subordinar/enquadrar/ controlar ou para ampliar possibilidades de produção da vida? Essas definições são importantes para os médicos (e trabalhadores da saúde em geral), independentemente da especialidade e local de trabalho.

Necessário importar médicos? Neste momento, sim, dada a dramática escassez experimentada não somente na atenção básica e nos lugares distantes ou muito pobres, mas, também, na urgênciaemergência, nos CAPS, nos ambulatórios de especialidades, nas UTIs etc.

Mas é preciso enfrentar o problema de modo incisivo. Ampliar as vagas de graduação, sim, mas não se apoiando no mercado (escolas privadas orientam-se pelo mercado e, visando ao lucro, seguirão nos grandes centros, de maior concentração de riqueza). É preciso assegurar que os estudantes oriundos dos bairros populares, das comunidades de trabalhadores rurais, indígenas e quilombolas tenham a possibilidade de ocupar um significativo número de vagas nos cursos de medicina. Cotas são importantes para isso, mas, também, é necessário regionalizar - possibilitar, por exemplo, que os estudantes da região Norte acessem as vagas ali existentes - coisa que nem o vestibular, nem o Sisu asseguram; os estudantes da região Sudeste têm ocupado a grande maioria das vagas dos cursos de medicina em todo o país.

Para mudar o perfil da formação - aí discordando das autoras -, a questão principal não é a pedagógica, a da relação saber-poder entre professores e estudantes. O embate principal se dá em torno da relação com os usuários: usuários-corpo (com órgãos e sem órgãos), usuários-objeto, usuários que devem ser submetidos pelos profissionais, aí, sim, numa relação saber-poder que recusa todo e qualquer saber que não seja fruto da ciência. Há que se fazer a vida e a produção do cuidado invadirem a formação. Não somente nas unidades básicas, mas, também, nos ambulatórios e hospitais, trazendo a integralidade e as tecnologias leves para o centro da cena. E não somente na graduação, mas, também, nas residências, em todas elas.

O PROVAB é uma medida em prol do provimento de médicos, especialmente, para os locais mais distantes. A iniciativa é válida, pois há a necessidade dramática de estratégias para se interferir num mercado de trabalho superaquecido e atrair médicos para a saúde da família. Mas o processo não é de valorização da atenção básica, já que o principal atrativo para os jovens médicos é, exatamente, o acréscimo na nota nos concursos para residência (por meio dos quais ascendem às especialidades e se distanciam da atenção básica).

Salário, moradia, acesso à internet e formação, boas condições de trabalho, mas não somente para os médicos, e, sim, para todos os trabalhadores da saúde. Boas condições de trabalho que não são apenas materiais, mas incluem a produção de espaços de construção compartilhada, de problematização, de produção de deslocamentos e que implicam outro encontro entre médicos e todos os outros trabalhadores da saúde.

Inclusive, trabalhando com um conceito ampliado de cuidado, a escassez de médicos pode ser uma boa oportunidade para se reinventarem as equipes e o trabalho interprofissional no SUS e para se reavaliar o que podem fazer as equipes em seus encontros com os usuários, no sentido da escuta, da desbiologização do viver, da produção mútua e do enriquecimento das existências. Oportunidade para desmanchar o critério médico-centrado para a legitimação de equipes! 